\title{
Semblanza biográfica de Ramón Echenique
}

\author{
por ALBERTO TAURO.
}

Ramón Echenique, segundogénito de Miguel Echenique y Ana Josefa Vásquez, nació en Valparaíso (1). Con su familia hubo de esiablecerse en Puno, a mediados de 1807. porque la ciudad natal se hallaba aparlada de las rutas comerciales y no ofrecia muy halagüeñasi esperanzas al espíritu de empresa. Eijtonces pudo iniciarse en la adminisiración colonial. Compartió con su hermano Jcsé Martin, las inquietudes que sembraron en la reción las marchas y contramarchas de reajistas y patriotas; y la estrecha comprensión enire ambos quedó ratificada el 13 de enero dej-1313, ten ja Paz. cuádo framón llevó a la pila bautismal a su sobrina Benita María.

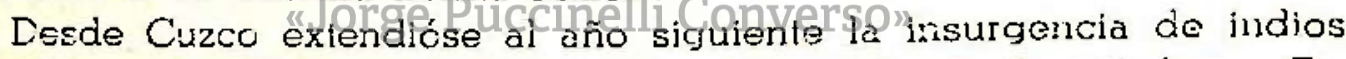
y criólos, acaudillados por el brigadier Mateo García Pumacahua. Estimulado por su devoción a la libertad, Ramón Echenique irabajó activamente para caralizar la ola revolucionaria que llevase hasta La Paz el presbíterc Ildetonso Múnecos, secundado por el coronel José Pinelo; con los galones de teniente coronel marchó en las huestes colecticias, cuando abandonaron la ciudad y, unidas a las del caudillo indio, se enfrentaron en el campo de Umachiri a las tropas del general Juan Ramírez; pero la situación fué dominada por los realistas, merced a la superioridad de sus recursos tácticos, y allí quedó Ramón Echenique entre ios numerosos prisioneros que debían redimir con suz dolor y su sangre la audacia de los insurgentes. Se le condenó a pri-

(1) El 21 de mayo de 1838 suscribió en Lima, ante el escribano José de Selaya, una escrilura donde consta aiue era "mayor de 40 años". $\Lambda$ base de dato tan impreLiso -sunque usual en la terminolegin atlluria" do la época-. sólo puede establecerse que nació anles de 1798 . 
sión perpetua, y para que la cumpliera se le trasladó, por disposición del virrey Abascal, a las Casas-matas del Real Felipe (Callao), donde ya se encontrabar los patriotas aprehendidos en las acciones de Ayohuma y Viluma. A su paso por Arequipa le fué encomendada la custodia de su sobrino José Rufino, que debía establecerse en Lima para seguir sus estudios; $\mathrm{y}$, lejos de mostrar el menor abatimiento, durante la travesia de Mollendo a Callao se esforzó por inculcar, a su ocasional pupilo, un claro concepto del deber que imponía a los americanos sobrellevar toda clase de trabajos que condujeran a la independencia.

Como todos los patriotes recluídos en las fortalezas, Ramón Echenique fué liberado en julio de 1821, en virtud del canje de prisioneros pactado entre los realistas y las fuerzas que habian tomado Lima. Sus antiguos servicios y su dilatado cautiverio hallaron entonces el merecido reconocimiento, y' Slan Martín dispuso (21 de julio) que se le extendiesen despachos de Sargento Mayor. No obstante, permaneció sin ocupación determinada hasta el 31 de diciembre; y sólo el 19 de enero de 1822 fué destinado como ayudante de campo del General Domingo Tristán, a guien se había encargado la preparación de operaciones diversionistas en el departamento de Ica. Salvó del desastre que en La Macacona sufrieron las fuerzas confiadas a dicho general, y el $1^{0}$ de mayo fué incorporado a la Legión Peruana, con la cual engrosó la división destacada hacia elesur, con la misión de delender los accesos dejolag eapital cýneperarocontzaslos realistas al mismo tiempo que las fuerzas enviadas a "intermedios". Y probablemente se hallaba en tal misión cuando fué ascendido a Teniente Coronel, el 3 de noviembre de 1822 .

Tras el fracaso de la expedición a "intermedios", prodújose en Lima un pronunciamiento militar, que impuso la elección del Coronel José Mariano de la Riva Agiuero como Presidente de la República. La Legión Peruana, fué inmediatamente considerada entre las fuerzas que debian llevar a cabo la proyectada intersección de las comunicaciones realistas, mediante una penetración desde los puertos "intermedios"; pero Ramón Echenique no participó en la nueva expedición, por ha- bérsele encargado (19 de abril de 1823) la inspección de los hospitales militares y, luego, las delicadas tareas correspondientes al Jefe de Estado Mayor de la Plaza Militar de Lima (26 de julio de 1823). Como tal, contribuyó a mantener la unidad del frente interno, cuando parecía que la pérdida de las fuerzas enviadas al sur habría de estimular la audacia de los godos; y no sólo asumió la responsabilidad de contener 
a realistas y desertores, sino la de auxiliar a los funcionarios a quienes competia recaudar las contribuciones que angustiosamente exigia la suerte de la patria.

En atención a la energía y la actividad que desplegaba, Ramón Echenique fué destinado (19 de enero de 1824) como ayudante del Presidenie de la República, Marqués de Torre Tagle. Pero éste había caído en el escepiicismo, efectuaba negociaciones secretas con los realistas y pronto defeccionó (27 de febrero); en tanto que su ayudante facilitó al General Mariano Necochea, la difícil misión de evacuar los hombres y materiales que podían coadyuvar a la prosecución de la gue rra, y marchó a unirse con los patriotas. Sucre le confió la Intendencia y Comandancia Militar de la provincia de Cajatambo, en el Departamento de Huaylas, y justificó el nombramiento advirtiendo a Bolivar (en carta del 7 de abril) que Karnón Echenique era "de los patriotas más conocidos y hombre honrado por su reputación". Dada la posición geogrática de aquella circunscripción, sus desvelos debieron aplizarse a la reunión de los elementos necesarios en la campaña que el ejército libertador había iniciado bajo las órdenes de Bolívar. Obtenida la victoria de junín, fué repuesto (octubre de 1824) en la jefatura de la Plaza Militar de Lima. Y afianzada ya la independencia, fué ascendido a "Coronel vivo y efectivo" de infantería, en atención a sus "méritos y servicios" "Degún reza el decreto supremo del 28 de febrero de 1825, autorizado por el Generaf formás Heres y refrendado por el vencedor de Junínowge EondécoradoCconvlardalla del Libertador.

Ramón Echenique fué trasladado en mayo de 1826 a la Prefectura del Departamento de Junín, cuya vinculación a los bancos de rescate de minerales determinaba su influencia en el fomento de la industria minera y en la prosperidad de la hacienda pública. Allí emprendió la rehabilitación de las minas derrumbadas e inundadas por los realistas durante la campaña emancipadora; dió las instrucciones convenientes para fijar su valor y el gravamen que debía imponérseles; y tuvo la satisfacción de diclar las providencias que entonces demandaban la recepción y el seguro traslado de las primeras maquinarias para la explotación de minerales, adquiridas en Londres por la Compañía Pasco Peruana. Efectuó una nueva matrícula de los contribuyentes, con el objeto de establecer una tasa ajustada a las mermas que las pasadas luchas habían acarreado a los negocios; y propuso que no fuese efectuada sólo por los intendentes y gobernadores, sino también por los párrocos, pues la estabilidad de éstos en sus respectivas localidades les infundía autoridad como testigos e informadores. Deslumbrado por 
la feracidad de los valles trasandinos, reunió los elementos adecuados para llevar a cabo la apertura de un camino de penetración a la montaña, y aun designó para este efecto al capitán de ingenieros Manuel Pando. Su gestión política fué absorbida por la consulta a los colegios electorales para que se pronunciase sobre la conveniencia de la constitución vitalicia; y por la celosa provisión de los fondos destinados al sostenimiento de las fuerzas que guarnecían la región. Pero, cambiada la orientación política del país con el pronunciamiento de las tropas auxiliares colombianas, y elegido diputado por la provincia de Puno, hubo de incorporarse al Congreso Constituyente reunido en mayo de 1827.

Las Juntas Preparatorias de aquel Congreso pudieron instalarse el 15 de mayo, y en ellas se acordó que Ramón Echenique integrase la comisión de asuntos militares. La legislatura se inauguró el 4 de junio, y al cabo de pocos días vióse envuelto el flamante parlamentario en una imputación difundida por L.a Cotorra con cartas de otro mundo (No 4, de 16 de junio de 1827), semanario que denostaba escandalosamente contra los vitalicios. Se le acusó de haber intentado reducir la voluntad de los nacionalistas peruanos, sometiéndolos a prisión mientras desempeñó la prefectura de Junín; y, en cambio, haberse comprometido a colocar este departamento bajo las órdenes de un coronel que el Mariscal Antonio José de Sucre, debía enviar desde Bolivia. Tan absurdo infundio no debió inspirar aaRamón Echenique sino el desdén; pero algún eco se lej dió en lac epinión. pues el d7 „de agosto denunció la publicación respectiva ante el jurado de imprenta y señaló como su autor al Coronel José Jaramillo, el cual fué absuelto por sentencia expedida el 19 de octubre; apeló el calumniado ante la Corte Suprema, sin obtener mejor resultado, pues aún admitiendo que se hubiese cometido delito de imprenta, dicho tribunal se excusó de aceptar una apelación enderezada contra sentencia que no había sido pronunciada conforme a las leyes, y se limitó a llamar la atención del Juez de Derecho - Ignacio Benavente- No era difícil hallar en este desenlace una comprobación de las implicaciones políticas del caso, y el Congreso Constituyente le puso término con una resolución 26 de enero de 1828) en la cual se estableció que Ramón Echenique estaba exento de culpa alguna, pues la imputación de La Cotorra con cartas de otro mundo era infundada y sólo obedecía al acaloramiento personal de su autor. Pero la justicia había afrontado el problema moral con pasos notoriamente tardos e inseguros; y esta experiencia la indujo a proponer la creación de un tribunal privativo que juzgase toda trasgresión de la 
ley cometida por los militares. Así afianzaba su adhesión a los princi. pios autoritarios y su oposición al grupo liberal del Congreso Constituyente.

Al renovarse la mesa directiva de éste, el 4 de inayo y el 4 de junio, fué elegido para ocupar una secretaría; y cuando llegaron a su término las tareas de esa asamblea legislativa (16 de junio). Ramón Echenique mantuvo el mismo cargo en la comisión permanente. Pero el presbítero Francisco Xavier de Luna Fizarro, afanóse para neutralizar su oposición y obtuvo del gobierno su nombramiento como Gobernador Militer del Cállao, en lugar del Coronel Manuel Larenas; y cuando se produjc el doble golpe de estado que los generales Agustín Gamarra y Antonio Gutiérrez de la Fuente organizaron, en Piura y Lima, Ramón Echenique aplaudió el cambio efectuado. Juzgó que el desplazamiento de los liberales implicaba el abandono de lo política antibolivarista, a la cual se debió la guerra peruano-colombiana; y reprochó al Libertador (20 de agosio de 1829 ) la concertación de la paz, porque ella impedía su posible retorno al Perú. En su calidad de Gobernador emprendió una activa persecución del contrabando, y llevó a cabo obrás de refacción en el muelle y en las fortalezas de Santa Rosa y El Sol. Aquejado por grave enfermedad, apartóse de su cargo en marzo de 1832; obtuvo licencia en junio; y, dada la confianza que su auhesión inspiraba al Presidente Gamarra sólo en noviembre fué sustituido por el Coronel José María Frías.

Debió confiar "elorestablecimientò Censüelsalud a la influencia del clima serrano; y luego se consagró a labores particulares y familiares (2), que no abandonó ya sino en forma efímera, pues las flaquezas físicas lo constreñían a evitar la tensión del servicio público. Por ineludible compromiso con el pronunciamiento del General Pedro Bermúdez, aceptó, en 1834, la Comandancia Militar del Departamento de Ju-

(2) En carta dirigida al Presidente Gamarra (8 de noviembre de 1833), el Minisiro de Guerra, Genera! Pedro Bermúdez, decia: "Hoy ha muerto el cura (Josó María) Echenique y U. puedo buenamente hacer lleque al conocimiento de D. Ramón por si importe que sepa esto. por sus intereses". Y como dicho cura., su hermano, lo hubiera confiado el cumplimiento de sus últimas disposiciones, en calidad de albacea lestamentario; Ran:ón Echenique presentóse ante el escribano Cayetano Casas (19 de octubre de 1835) y otorgó poder a Salvador Piedra de la Fuente, domiciliado en Valparaíso, para que cobrase a su madre, Carmen de la Fuente, la cantidad de 25 pesos anuales, a la cual ascendía el gravamen que pesaba sobre la casa que había heredado de Ana Josefa Vásquez de Echenique y que ésta había eslablecido en benelicio de su hijo José María. 
nín, $Y$, triunfante el régimen legal por efecto del "abrazo de Maquinguayo", solicitó su retiro. Al año siguiente contrajo matrimonio con Dolores Alvariño Bermúdez, viuda de Blas Segovia, a la cual sustituyó en la curatela de su hijo Pablo (3). Arrendó una chacra próxima al puéblo de Magdalena, perteneciente al Convento de la Buena Muerte y conocida, por eso, como la "chacra de la Buena Muerte"; pero, no obstante la apreciable demanda que en la capital tenía su producción de forraje, apenas cubría los 800 pesos anuales de la merced conductiva y la alimentación de los esclavos (4). que la cultivaban. Designado para representar al Departamento de Junín en la Asamblea de Huaura, y elegido vicepresidente de ésta, contóse entre los fundadores de la Confederación Peruano-Boliviana y fué distinguido con la medalla de Oficial de la Legión de Fonor que instituyó el Protector, Andrés de Sanla Cruz. Luego reanudís sus proplas ocupaciones. Y no cabe duda que entre propios y extraños, debieron ser muy apreciadas sus do-

(3) Dolores Alvarino viuda de Serovia y su hijo Pablo Segovia, mayor de 14 años, so presentason (9 de julio de 1835) anle el Juzgado de Primera Instancia que conduría Antorio Carrasco, $\gamma$, acluando el escribano Baltazar Núñez del Frado: la prímera renunció a ejercer la curatela de su hijo y solicitó que en su lugar fuese nombrado Rimón Echenique, $y$ el menor accedió a la sustilución. Al día siguiento, el nuevo curador clsació la fisriza de Pedro Ancieta, propietario conocido de la ciudad do Linn; $y$, acto secuuido, otorgó poder a José: Benito Illónez, vecino do Cerro de Fasco, parabulue entablese demanda conla Marama Segovia, por el valor de la milad de una casa situzda el Tarma que correspondía los bienes heredacios por su pupilo y aquellahabia vendidejunamente conla mitad que le perlenecia. Pero no debió ser muy acliva ni elicaz la gestión del apoderado, pues el 7 de mayo de 1841. y ante Josó Simeón Ayllón Salazar, olorgó poder a Francisco Cuba para que llevase a cabo el mismo encargo.

En ejercicio de la curatela del menor Pablo Segovia, presenlóse Ramón Echenique arte el escribano Josá Simeón Ayllón Salazar (10 de meyo de 1838) y olorgó poder a Mariano jimbnez para que lo representuse en pleilos.

(4) En aquellos años ele tús numerosos contralos de compra venta de esclavos. Ante Cayelano Casas compra: a Petronila Muñoz. un negro llamado Félix, por el cual paga 300 pesos (14 de noviembre de 1835); a Clara Arróspide, un zambo llamado Mariano, en 210 pesos (10 de junio de 1836): a José Maria Paredes, una negra llamada Juana Paula, por 250 pesos (16 de junio de lâ36): a Hilario Agüero, una negra llamada Vicenla Toledo, en 230 pesos $\left(1^{\circ}\right.$ de diciembre de 1836). Y anle Jo sé Simeón Áyllón Salazar vende a Manuel Laos, quien se halla en Huaura y es representado por su padre José Lzos, una zamba llamada Sanción, por la cual recibe 250 pesos (9 de abril de 1838); vende a María Reyes, un zambo llamado Mariano, por 250 pesos (29 de diciembre de 1838); y cede a Juana Saavedra el derecho de patronato sobre su hijo, un negro liberto de 12 años, llamado Domingo de Guzmán (lí de enero de 1839). 
tes personales, pues se le confían entonces muy delicados encargos: por disposición testamentaria del Coronel José Santos Súnchez, comparte el albaceazgo con su viuda, María Laos (5); mediante acuerdo privado, habilita al comerciante Eernardo Iturrizaga para que pueda rematar los diezmos de la provincia de Jauja $y$, aunque éste garantiza el dinero recibido mediante una participación equivalente a la tercera parte de la renta por cobrar, Ramón Echenique opta por el reembolso (6); después de asistir durante sus postreros instantes al arzobispo Jorge Benavente, atiende sus recomendaciones póstumas, en calidad de albacea testamentario (7); y aún el clérigo Estanislao Márquez - en visperas de dirigirse a Jauja para ocupar el curato del lugar —, le otorga poder

(5) Fué instiluído como tal por expresa voluntad del Coronel josé Santos Sánchez, misnifestada ante José Simeón Ayllón Salazar el 21 de mayo de 1836. Y desompeñó el cargo con tal desprendimiento que María Laos viuda de Sánchez declaró, ante el mismo actuario (2.1 de inarzo de $18 / 11)$ que Ramón Echenique no tenía respon. sabilidad alguna en el manejo de las sumas recibidas por la testamentaría, pues ella funujía como tesorerà y aquel se limitaba a firmar los documentos respectivos, con el ánimo do que no se interrumpiese "el pronto curso" de los asuntos pendientes.

En su calidad de albarrea testamentario del Coronel José Santos Sánchez ,Ramón Echenique intervino: en el pago de 312 pesos -debidos por 8 semestres do intereses de un capital de 2000 pesos que, al 3 por ciento, gravaba una casa de la calle Esplana- hecho a Manuel de León, síndico del Convento de San Francis. co, ante Juan der Dios Gorenóc(200ndel setiembreedgo1836); en la compra de una esclava de 28 años, llamada Juana Evangelista, que Josefa vendió a María Laos viuda de Sánchez y por la cual pagó ésta la cantidad de 350 pesos, ante José Simeón Ayllón Salazar (15 de enero de 1841); y ante el mismo actuario, en el arreglo negociado con Ignacio Jdría sobre pago de arrendamiento de la llamada "chacra de Chavarría", conducida por aquél (5 de agosto de 1841).

(6) Ante el actuario José de Selaya, Rarnón Fchenique suscribió: 1ㅇ, un poder a favor de Bernardo Iturrizaga, para que cobrase la tercera parte de los diezmos de la provincia de Jauja ( 1 \% de agosto de 1837); 29 , venta cle su participación en los diezmos por 1500 pesos (2] de abril de 1833); y 3ㅇ. transacción sobre pago do un saldo de 1255 pesos, que Bernardo Iturrizaga debía efectuar por mensualidades do 69 pesos 6 reales y 30 pesos 2 reales, abonables en Lima y Cerro de Parsco al propio Ramón Echenique y a su apoderado Jcsé Benito Illánez, respectivamente, o, en caso fortuito, abonables sólo en Cerro de Pasco los 100 pesos de cada mensualidad (22 de mayo de 1833).

(7) Ante José Simeón Ayllón Salazar, y a nombre de la testamentúría del Arzobispo Jorge Benavente, Ramón Echenique otorga poder al procurador de la Corte Superior de Lima, Andrés Angulo, para que lo represente en juicio (23 de julio de 1839). 
(8) para cobrar judicial o extrajudicialmente las cantidades o efectos de que era acreedor. Pero la tuberculosis minaba su existencia y, como años atrás. hubo de buscar alivio en las alturas serranas. El 8 de abril cie 1843 otorgó poder a Andrés Anculo, procurador de la Corte Superior de Lima, para que lo representase en los litigios que tenía pendientes; dos días más tarde subarrendó la "chacra de la Buena Muerte" al General Pedro Rermúdez; el 11 suscribió su última disposición ante los generales Juan Pardo de Zela y Clenente Ramos, en armonía con las crdenanzas militares; y luego marchj a ocupar la subprefectura de la prcvincia de Jauja, donde había de interponer su ascendiente personal para borrar los éeclos de la reciente disputa por el poder. Alli, e? Jauja, murió, durante el mes de mayo de aquel año.

De acuerdo con el testamento que suscribiera en Lima el 11 do abri! de i343, actuaron como aibaceas de la sucesión de Ramón Echenique, su propia esposa y sus sobrinos José Rufino y Nicasio Echenique. Sus bienes paternos y maternos fueron legados, por partes iguales, a sus hermanos Manuel y Miguel - a la sazón residentes en La Paz y a sus sobrinos Carlota, Benita María y Juan Martín. De sus bienes personales (9) deió como heredera a su esposa, Dolores Alvariño Bermúdez, con la obligacićn de atander dos legados: uno, en favor de Flora - o Florentina, hija del testador y de Rosa Salazar, nacida en Lima el 15 de marzo de 1826, jy bautizada en el Sagrario de la Catedral el $1^{\text {n }}$ de junio del mismo año 1 , por un totai de 3000 pesos, que debían serle entregados en calidadojededotegchnes lictales perdía derecho si su conducta no fuese correcta; y otro, de 2000 pesos, en favor de María Oje. da, cuya paternidad se le atribuía y a quien decidió beneficiar sólo por haber tomado su apellido.

(8) Extendido anle José Simeón Ayllon Salazar (15 de diciembre de 1840). para cobrat cuanto se le debía o debiere "en virlud de escrituras, pagarés, libranzas, endosas, reconocimientos del crédito púbiico. billetes, contralos, réditos de capellanía" o cualquier otro concepto.

(9) Inventario y lasación de lales bienes, fueron protocolizados ante José Simeón Ay. lón Salazar, el 11 de mayo de 1844. Aparte de los muebles y enseres correspondientes a una sencilla vivienda, figuran allí 10 esclavos, 192 peses y 4 reales en dinero efeclivo, y los sueldos adeudados por el gobierno. Sus ropas y demás objelos de uso personal fueron quemados. 